\title{
El periodismo literario del conflicto en Colombia: Olga Behar, El clan de los doce apóstoles y María T. Ronderos, Guerras recicladas
}

\section{Literary Journalism of the Conflict in Colombia: Olga Behar, El clan de los doce apóstoles and María T. Ronderos, Guerras recicladas}

\begin{abstract}
Resumen
El conflicto armado en Colombia ha generado un flujo de material periodístico y literario que intenta entender y reflexionar sobre la violencia que permea el país. Contar los hechos se ha convertido en un deber, y analizarlos a la luz de la verdad, en una responsabilidad. Este ensayo analiza dos obras representativas del periodismo literario que han generado impacto en la opinión pública y que a la vez han develado asuntos de trascendencia en el acontecer nacional en los años recientes: El clan de los doce apóstoles de Olga Behar (Icono, 2011) y Guerras recicladas: una historia periodística del paramilitarismo en Colombia de María Teresa Ronderos (Aguilar, 2014). El objetivo es explorar las técnicas narrativas que utilizan las autoras para generar conciencia crítica sobre uno de los movimientos que tuvo mayor impacto en el conflicto armado en Colombia, el paramilitarismo. Se analizan las técnicas narrativas a partir de los conceptos studium y punctum planteados por Roland Barthes en Camera Lucida como estrategias discursivas para transmitir un mensaje poderoso sobre la realidad colombiana.
\end{abstract}

Palabras claves

periodismo literario, crónica literaria, studium, punctum, paramilitarismo, conflicto armado, 


\begin{abstract}
The armed conflict in Colombia has generated a flow of journalistic and literary corpus that aimed to understand and reflect upon the violence that permeates the country. Telling the facts has become a duty, and analyzing them in the light of the truth, a responsibility. This essay analyzes two representative works of literary journalism that have had an impact on public opinion and, furthermore, have revealed important issues about recent national events: El clan de los doce apóstoles (The Twelve Apostles Club) by Olga Behar (Icono, 2011) and Guerras recicladas: una historia periodística del paramilitarismo en Colombia (Recycled Wars: A Journalistic History of Paramilitarism in Colombia) by María Teresa Ronderos (Aguilar, 2014). The objective is to explore the authors narrative techniques to create critical awareness about one movement that generated the major impact on Colombia's armed conflict: the paramilitarism. I analyze the narrative techniques building upon the concepts studium and punctum proposed by Roland Barthes in Camera Lucida, as discursive strategies for transmitting powerful messages about Colombian realities.
\end{abstract}

Keywords literary journalism, literary chronicle, studium, punctum, paramilitarism, armed conflict, Colombia.

Una sociedad que le teme a la verdad se convierte en una sociedad mal informada, y una sociedad sin información no solo es más manipulable sino que está expuesta a que los que tienen la sartén por el mango abusen de los demás.

María Jimena Duzán

La noticia diaria tiene el deber de construir la historia paso a paso. La literatura tiene el poder de analizarla a luz de la distancia y el tiempo. La confluencia de ambas genera el periodismo literario, cuya labor se convierte en la construcción de la memoria histórica. El conflicto armado en Colombia ha generado un flujo de material periodístico, narrativo y literario que intenta entender y reflexionar sobre la violencia que permea al país. Contar los hechos se ha convertido en un deber, y analizarlos a la luz de la verdad, en una responsabilidad.

En años recientes, varios periodistas han incursionado en la tarea de contar las verdades ocultas de la historia a través de crónicas, reportajes, fotografías, videos y otras formas que permiten entrever los entramados intrincados de la 
guerra. En cualquiera de sus formas, la labor del periodista es registrar la historia y dejar plasmado un testimonio de los actores involucrados.

El discurso narrativo que nutre este género se mueve entre el periodismo y la literatura. Se le llama Nuevo Periodismo, Periodismo Literario, Literatura de hechos, Literatura de no ficción, Periodismo Personal. También se le ha denominado Paraperiodismo o el arte de narrar en el periodismo (Hoyos 2003). Este tipo de narrativa toca elementos de las ciencias sociales, como la antropología, la sociología y la historia, pero también las distintas disciplinas toman elementos de él (Puerta 50).

El periodismo como discurso comparte distintas características con la escritura que se considera tradicionalmente literaria. Andrés Puerta afirma que "como arte del lenguaje, el periodismo no es una imagen que refleja la realidad, sino una construcción, una representación de esta. Y construcción quiere decir que es una producción discursiva, con todas las características que puede tener una obra literaria" (51). Es decir, que como discurso, el periodismo encierra la misma intencionalidad que la literatura: construir una representación subjetiva de la realidad.

En este ensayo me interesa analizar unas de las narrativas que han generado impacto en la opinión pública y que a la vez han develado asuntos de gran trascendencia en el acontecer nacional en los años recientes. Me enfocaré en las crónicas: El clan de los doce apóstoles de Olga Behar y Guerras recicladas: una historia periodística del paramilitarismo en Colombia de María Teresa Ronderos. El objetivo es explorar las técnicas narrativas que utilizan las autoras para revelar hechos inéditos y para generar conciencia crítica sobre uno de los movimientos que tuvo mayor impacto en el conflicto armado en Colombia, el paramilitarismo. Para esto, analizaré las estrategias narrativas a partir de los conceptos studium y punctum propuestos por Roland Barthes. Por último, abordaré el impacto que han tenido estas obras en la construcción de una memoria histórica del conflicto. 
CATEDRAL TomAdA: Revista de crítica literaria latinoamericana / Journal of Latin American Literary Criticism

El periodismo literario del conflicto en Colombia: Olga Behar, El clan de los doce apóstoles y María T. Ronderos, Guerras recicladas

\section{Studium y Punctum}

En Camera Lucida Roland Barthes establece una distinción entre el studium y el punctum. En fotografía, el studium se refiere a la visión panorámica de una imagen, mientras que el punctum se enfoca en el detalle. Es decir, que el studium pasa por encima de la situación, al tiempo que el punctum permite observar más allá, lo que no se ve y lo que no se dice, pero que aparece como una forma de trascender la imagen y de "estar ahí" (Barthes 47).

Barthes explica que el studium genera una emoción de interés humano ante un testimonio político y cultural representado en la imagen. El punctum por su parte, genera empatía, una forma de punzada o de cortada como la producida por un instrumento corto punzante (Barthes 26). Yo propongo que las narrativas que comprenden la historia de Colombia reciente se debaten entre estos dos elementos, el studium y el punctum. Mientras la noticia del día a día disemina una variedad de mensajes con dispersión, un libro concentra la atención en los hechos puntuales. Las crónicas, reportajes y formas narrativas y visuales aparecidas en los años recientes sobre los eventos más dolorosos de la historia de violencia en Colombia convocan al lector y producen ese efecto de punctum señalado por Barthes. Es la punzada que produce dolor ante los hechos violentos registrados en estas narraciones.

¿Por qué en Colombia no se conocieron las atrocidades cometidas por las fuerzas militares y paramilitares hasta el segundo decenio del milenio? Se podría pensar que el discurso mediático se enfocó en un solo objetivo: la guerrilla de las FARC. La opinión pública fue manipulada como una piel social que sólo concebía un enemigo común y la sociedad en pleno aprobaba las medidas que se tomaran para recuperar la sensación de estabilidad a cualquier costo.

Cuando se empezó a revelar que las mayores atrocidades, masacres, homicidios múltiples, desplazamiento y desapariciones eran cometidas por los paramilitares, la ciudadanía se negó a creerlo ${ }^{1}$. Tan persuasivo era el mensaje. Aún

${ }^{1}$ Según el informe ¡Basta Ya! del Centro Nacional de Memoria Histórica, "los paramilitares implementaron un repertorio de violencia basado en los asesinatos selectivos, las masacres, las 
hoy, tras revelarse toda la maniobra desatada por las fuerzas militares, estatales y paramilitares, la opinión pública sigue sosteniendo la agenda generada por una opinión pública moldeada por el discurso oficial.

Las obras periodísticas que revelan la historia del paramilitarismo y sus aliados, El clan de los doce apóstoles de Olga Behar y Guerras recicladas de María Teresa Ronderos, fueron publicadas en el 2011 y 2014 respectivamente. En ambos libros se revelan los crímenes cometidos por la alianza de fuerzas militares y paramilitares y, además, por parte de los miembros del gobierno regional y nacional. La obra de Behar se refiere a uno de los bloques más notables de las autodefensas, Los doce apóstoles. La narración se enfoca en la formación y actuación de dicho grupo a través de la entrevista realizada a un miembro retirado de la Policía nacional. Las revelaciones del libro han señalado a unos de los personajes más poderosos del país y han generado investigaciones judiciales que actualmente están en proceso. El texto de Ronderos, por su parte, se refiere a la historia del paramilitarismo desde sus orígenes, a través de una investigación profunda que devela la conformación de los grupos, los personajes que los apoyaron, y el legado que sigue permeando en la sociedad. Ambos libros ponen sobre el tapete la ausencia de registro por parte de los medios nacionales sobre los verdaderos culpables de los hechos sangrientos que vivió el país.

desapariciones forzadas, las torturas y la sevicia, las amenazas, los desplazamientos forzados masivos, los bloqueos económicos y la violencia sexual. Las guerrillas recurrieron a los secuestros, los asesinatos selectivos, los ataques contra bienes civiles, el pillaje, los atentados terroristas, las amenazas, el reclutamiento ilícito y el desplazamiento forzado selectivo. La violencia de los miembros de la Fuerza Pública se centró en las detenciones arbitrarias, las torturas, los asesinatos selectivos y las desapariciones forzadas, así como en los daños colaterales producto de los bombardeos, y del uso desmedido y desproporcionado de la fuerza. De las 1.982 masacres documentadas entre 1980 y 2012, los grupos paramilitares perpetraron 1.166 , es decir el 58,9\% de ellas. Las guerrillas fueron responsables de 343 y la Fuerza Pública de 158, lo que equivale al $17,3 \%$ y $7,9 \%$ respectivamente" (33-34). Esto indica que los paramilitares fueron responsables de los actos de mayor violencia en el país. 
CATEDRAL TomADA: Revista de crítica literaria latinoamericana / Journal of Latin American Literary Criticism

El periodismo literario del conflicto en Colombia: Olga Behar, El clan de los doce apóstoles y María T. Ronderos, Guerras recicladas

\section{El periodismo narrativo}

"La crónica es un género latinoamericano, con fuerte acento colombiano", dice Andrés Puerta (55). Resalta que

la crónica es uno de los géneros más ricos, más elaborados, que más relación tiene con la literatura: es una zona de tránsito libre donde confluyen distintas disciplinas: es narrativa, descriptiva y opinativa... La crónica representa la realidad, y la realidad está plagada de protagonistas; por eso se convierte en un género de expresar la vida misma, a través de distintas maneras de narrar. (55)

La crónica y el periodismo narrativo son unos de los géneros que más han influido en el desarrollo de la escritura en América Latina y en Colombia, desde los cronistas de Indias. durante la conquista, hasta la independencia, relatos como $E l$ Carnero de Juan Rodríguez Freile (1638), influyeron significativamente en la forma de narrar. Esto se debe a las características que provee el periodismo narrativo: revela hechos reales, narrados con lujo de detalles y una línea argumental que emplea el lenguaje literario. En palabras de Puerta:

El periodismo narrativo es una forma de escritura que por sus características, que incluyen encontrar personajes, recrear acciones y contextos, ha sido un modo para mantener una memoria viva de las civilizaciones, una historia que palpita y está viva y que cobra validez cada que alguien se dedica a estudiarlos. (47)

Este género ha tenido diversas denominaciones: periodismo literario, nuevo periodismo, crónica y reportaje de profundidad. Puerta admite que prefiere periodismo narrativo a periodismo literario por la posibilidad de que ofrece la narración de captar y dejar huella de las acciones humanas, a través de géneros como el reportaje, la crónica, la entrevista, el perfil y el testimonio (47). 
Es cierto que hay muchos ejemplos de otras latitudes, como lo que se llamó la escritura de "no ficción" representada por la obra de un autor norteamericano que cambió la forma de contar, Truman Capote con su novela A sangre fría (1966). Puerta afirma que "este tipo de periodismo se vale de unas técnicas similares a las de la literatura, como contar el relato escena por escena; el manejo del tiempo y la tensión para crear atmósferas y dar cuenta de los hechos (48). En el caso latinoamericano, Gabriel García Márquez fue el maestro de las crónicas literarias con obras como Relato de un náufrago (1970), Crónica de una muerte anunciada (1981) y Noticia de un secuestro (1996). En todos estos casos, el periodismo narrativo mantiene el compromiso con la verdad de los hechos, pero también con el componente estético.

En Colombia, el periodismo narrativo ha tenido un gran auge como resultado del conflicto armado de larga duración. Los periodistas y escritores se han visto obligados a narrar la historia presente desde una perspectiva de lo inmediato a través de narraciones testimoniales y factuales. Desde los años sesenta se ha dado una producción cíclica de obras periodísticas que intentan plasmar la historia del conflicto. Son relatos de guerra, pero con un sentido humano. Los medios se cansan de producir noticias diarias de la guerra en todos los rincones de la geografía nacional. Según Mary Luz Vallejo, estas noticias "terminan por volverse inaudibles, invisibles, inapreciables, como si detrás de cada asalto guerrillero, de cada masacre, de cada atentado y de las cifras oficiales de víctimas, no hubiera un montón de vidas por contar" (138). Es entonces cuando los cronistas recogen la memoria de los testigos, sin prisas, para narrarla con géneros de más largo aliento como la crónica y el reportaje (Vallejo 138).

Los periodistas colombianos intentan comprender la realidad a través de centrarse en un tema y de ahondar sobre el mismo. Así, los episodios dispersos adquieren contorno y contexto. En una entrevista con Martha Ruiz, Álvaro Sierra describe la función del periodismo: "Cuando tú adoptas una posición militante a favor de ideas como la paz, los derechos humanos o el medio ambiente, pierdes en 
CATEDRAL TomADA: Revista de crítica literaria latinoamericana / Journal of Latin American Literary Criticism El periodismo literario del conflicto en Colombia: Olga Behar, El clan de los doce apóstoles y María T. Ronderos, Guerras recicladas

cierta medida la capacidad de explicar. La función del periodismo en un conflicto, ante la inequidad es explicar, explicar, y explicar" (Ruiz np).

Olga Behar señala que la función primordial del periodismo es la de construir memoria histórica desde el periodismo. Explica que los periodistas cuentan con la experiencia, las herramientas y la capacidad para generar confianza entre protagonistas, testigos y, también, entre quienes tienen a su disposición para cuestionar, contrastar, corroborar y/o rechazar los testimonios de viva voz. Todos estos elementos conducen al propósito "de reconstruir una memoria colectiva que permita entender qué sucedió, pero principalmente cómo y por qué y para qué" (Pistas 53) Según ella, las respuestas a estas preguntas contribuirán "a sanar, a perdonar, a reparar las heridas y a trazar una ruta hacia la no repetición, ni de estos, ni de nuevos actores. Para pasar la página y crear nuevas condiciones de convivencia. Una sociedad que no sea suficientemente informada sobre su pasado no entenderá por qué debe construir un futuro diferente" (Pistas 53).

Es así como a finales de los sesenta y principios de los setenta surgieron reporteros como Daniel Samper Pizano, Germán Castro Caycedo, Alberto Zalamea, Germán Santamaría, Javier Darío Restrepo, Alfredo Molano y otros que empezaron a recoger historias a lo largo y ancho del país y a convertirlas en obras completas. En los años ochenta le siguieron Arturo Alape, Patricia Lara, Olga Behar, Laura Restrepo, Gloria Pachón y Alonso Salazar, entre otros. En esta época se recrudeció la escalada de la violencia y se hizo menester mediar los acontecimientos a través de la pluma y la perspectiva analítica del cronista. De acuerdo con Vallejo, los documentos periodísticos sirven de "antídoto contra la desmemoria" y al consultarlas cada cierto tiempo comprobamos que "la historia se repite cíclica y cínicamente en nuestro país" (139). En los años noventa surgen otro tipo de crónicas, como Años de fuego, un proyecto coordinado por Carlos Uribe de los Ríos y Juanita León que recogió más de 20 reportajes representativos de la década. Sobresalen en esa época también las crónicas de Alfredo Molano y Germán Castro Caicedo, dos cronistas que cambiaron la forma de contar historias desde el 
periodismo narrativo. Estas obras lanzaban una propuesta de penetrar en la condición humana tanto de los guerreros como de las víctimas.

Olga Behar y María Teresa Ronderos cumplen con los postulados del periodismo en cuanto a la labor social de informar, contextualizar y argumentar sobre hechos que han tenido un impacto, pero también sobre aquellos que fueron ignorados deliberada o accidentalmente por los medios. Sobre este tema versan los libros que analizo a continuación.

\section{El clan de los doce}

En el año 2011 Olga Behar publicó El Clan de los doce apóstoles: conversación con el mayor Juan Carlos Meneses. Este fue uno de los primeros libros que reveló la magnitud de la violencia provocada por uno de los grupos paramilitares en Colombia. El texto se puede clasificar dentro del reportaje de investigación periodística, ya que se basa en una entrevista de largo alcance con uno de los integrantes que se atrevió a revelar con lujo de detalles la conformación del clan, sus líderes, el modo de operación, su propia participación en los crímenes y las razones que lo llevaron a exiliarse. El reportaje se complementa con las descripciones pormenorizadas de los contextos históricos y geográficos, los personajes y las circunstancias donde ocurrieron los hechos.

Con este libro Olga Behar se consolidó una vez más como referente en la tradición periodística de finales de siglo veinte y principios del dos mil. Ya en los años ochenta, Behar se había hecho merecedora tanto de reconocimientos a su labor, como también de persecuciones por sus libros Noches de Humo (1986) y Las guerras de la paz (1990). Estas obras recogían testimonios sobre el Holocausto del Palacio de Justicia y entrevistas a integrantes del movimiento M-19, uno de los grupos guerrilleros que causó conmoción en el país. Olga Behar se vio obligada a exiliarse de Colombia por amenazas de los mandos militares de la época. A su regreso a Colombia, ha continuado realizando periodismo de investigación con publicaciones como El clan de los doce apóstoles (2011), El caso Klein: el origen del paramilitarismo en Colombia (2012), La paz no se rinde: crónicas y memorias 
de los acuerdos de La Habana (con Carolina Ardila y Pablo Navarrete, 2018), Lo que la guerra se llevó: veinte voces que retratan medio siglo de conflicto en Colombia (con carolina Ardila y Pablo Navarrete), Operación Palomera: el comienzo del fin de las FARC (con Pablo Navarrete, 2019). Behar ha recibido el premio de periodismo Simón Bolívar y otros reconocimientos a su labor. Actualmente es docente universitaria en varias facultades de comunicación y periodismo en Cali, Colombia.

En el prólogo de Las guerras de la paz, Antonio Caballero se refiere al silencio que rodeaba las actuaciones de los poderosos frente a la violencia que azotaba al país en 1985:

Olga Behar no toma partido: toma nota, simplemente. No trata de lucirse ni de hacer literatura $[\ldots]$ Son entrevistas con nuestra historia secreta, oculta, ocultada. Este libro, que no quiere ser más que una recopilación imparcial de testimonios personales, es un instrumento fundamental para entender qué es lo que nos está pasando. (Las guerras de la paz 9)

Estas mismas palabras escritas hace casi cuarenta años se podrían aplicar a El Clan de los doce apóstoles. Este libro intenta abordar el fenómeno del paramilitarismo desde un punto nodal, el de un grupo emblemático conformado por grandes personalidades políticas, auspiciado por gremios económicos y eclesiales y apoyados por las fuerzas militares y policiales. Como expresa Antonio Morales Riveira en el prólogo:

Este libro de Olga Behar necesariamente será un texto clave para comprender todos esos intríngulis y fenómenos del horror de la alianza Estado-paramilitares. Clave porque revela el material de las estructuras paramilitares y porque nos cuenta a través del relato crudo, del dato y la anécdota, los detalles, los modus operandi de estos criminales. (El Clan 15) 
En efecto, El Clan de los doce apóstoles relata la historia del teniente Juan Carlos Meneses en sus propias palabras. Meneses era el comandante de la Policía en Yarumal, Antioquia. Allí conoció a los grupos que él denomina "de limpieza social". En ese proceso se encuentra con los integrantes del clan conocido como Los doce apóstoles compuesto por campesinos y hacendados de la zona. Su líder era Santiago Uribe Vélez, miembro de una familia muy reconocida a nivel político y empresarial. Este clan tenía su sede de operaciones en la finca La Carolina, donde se ofrecía el adiestramiento militar y se tomaban las decisiones. El relato aborda los pormenores de la conformación del clan, la estructura de mando y su modo de actuar. Revela también las redes que mantenían con las autoridades políticas de la región y con los mandos de la iglesia (uno de los párrocos del pueblo era miembro del clan). El diálogo con Meneses es crudo y desapasionado. Con sutil maestría la autora permite revelar la personalidad del entrevistado sin recurrir a juicios ni interpretaciones. En algunos pasajes se evidencia el estoicismo del personaje cuando relata el modus operandi del grupo y las acciones criminales que él ampara como jefe de la policía del pueblo. Una de las estrategias del Clan es la de asegurar el silencio sobre sus procedimientos sin importar los métodos. Meneses explica: Los mismos apóstoles hacen asesinar a todos los sicarios, los mismos paracos los matan para taparles la boca, porque el que sepa algo tiene que salir del mapa, ya no queda nadie de los que trabajaban en la base (El Clan 77).

Así se descubre que todos los colaboradores del comando eran asesinados para no dejar cabos sueltos. El teniente revela que no sólo eran eliminados los enemigos contra quienes se libraba la guerra, sino contra los que les hacían los trabajitos sucios. En este pasaje Meneses ilustra la dinámica de la violencia política infiltrada por los actores armados:

Cuando se sabe algo de una persona que no va en ascenso político no pasa nada, pero si los vinculados tienen aspiraciones de alto vuelo, pues no le conviene ese riesgo. Ya sabe usted que en estas circunstancias saber 
CATEDRAL TomAdA: Revista de crítica literaria latinoamericana / Journal of Latin American Literary Criticism

El periodismo literario del conflicto en Colombia: Olga Behar, El clan de los doce apóstoles y María T.

Ronderos, Guerras recicladas

demasiado, y sobretodo si se sabe más de la cuenta sobre la familia Uribe, se paga con la vida. (El Clan 81$)$

De esta forma descarnada y brutal, Behar destapa el accionar de uno de los grupos más criminales del país y el nexo con los estamentos gubernamentales. El paramilitarismo fue mucho más que un grupo armado que sembró el terror, fue una política de Estado orquestada por los gremios económicos y manejada desde arriba por las autoridades a nivel regional y nacional.

La alusión al célebre político, hermano del líder del clan, y quien llegó a ser presidente de Colombia, discurre a lo largo de las páginas como personaje clave y siniestro. Su mención se hace primero con admiración, y luego, a medida que se desarrollan los acontecimientos, con miedo y con el desencanto de sentirse traicionado. Sin embargo, el teniente no tiene contacto directo con él, sino con su hermano, quien es el líder del Clan. Meneses relata en forma muy ilustrativa el encuentro con Santiago Uribe:

A ver le cuento de nosotros; aquí tenemos unos muchachos, una gentecita [...] nosotros vamos a ser fundamental para el trabajo suyo, vamos a apoyarlo en todo lo que usted necesite, pero de usted necesitamos el apoyo también[...] El objetivo mío es acabar con las FARC y al ELN en esta región[...] limpiar la zona. (El Clan 106)

Meneses comprende que su trabajo consiste en proteger las actuaciones del grupo y no intervenir ni dejar que ninguna autoridad intervenga cuando se efectúen asesinatos y masacres. A cambio de esta protección, el líder le asegura que no debe preocuparse porque los mandos políticos y gente de la clase política en Medellín y Bogotá, saben sobre sus gestiones (El Clan 107). Le advierte, además, que él debe colaborar con una amenaza implícita de que si no lo hace, se verá en problemas. Al final le asegura: Usted no tenga ningún temor, porque esto lo conoce el comandante del departamento, lo conoce la brigada, lo conoce mi hermano que es político, y él 
tiene muchos amigos[...] tenemos manejo a nivel nacional (mi subrayado El Clan 107). Llama la atención la audacia con que Meneses se refiere a este personaje poderoso, que al final termina traicionándolo, amenazándolo y persiguiéndolo por haber incumplido el pacto secreto de silencio y lealtad.

El otro asunto que da a conocer a través del diálogo con el policía es que el objetivo de los paramilitares no era acabar con la guerrilla, sino quedarse con el negocio del narcotráfico. El plan era despejar la ruta del narcotráfico desde Antioquia, pasando por el Magdalena Medio, atravesando el departamento de Córdoba hasta la costa Atlántica donde se enviaban los cargamentos. Las alianzas entre los bloques se afianzaron en los años noventa, especialmente gracias al poder que alcanzaron los hermanos Castaño en Córdoba y el bloque de Salvatore Mancuso en la Costa. Meneses ratifica que "el objetivo de Santiago al combatir la guerrilla era quitarle el poder del narcotráfico, y usted mira que ya desde 1993 hasta 2005 las autodefensas se apoderaron de todo ese sector" (El Clan 112).

Un aspecto que sorprende es la relación de los paramilitares con las fuerzas militares. Explica que el Ejército carecía de control sobre la guerrilla. Solo atacaban a la guerrilla cuando esta los hostigaba. En cambio los aras $^{2}$ sí actuaban sin miramientos contra la guerrilla y los que tenían vínculos con ellos. La razón era que los ellos tenían conocimiento del terreno y del modo de pensar de los guerrilleros. Esto explica que el Ejército pusiera su confianza en los bandos paramilitares con la anuencia del Estado. El argumento que prevalece aún era que la guerrilla era el enemigo, que parecía imposible vencer y cualquier método para derrotarlos se justificaba. Al mismo tiempo, una de las estrategias que sobresale en la narración era la consigna de atribuir la culpa a la guerrilla de los operativos cometidos por las autodefensas y los militares. Así se lograban dos propósitos: arreciar el odio contra los subversivos y la adhesión de la opinión pública a su favor.

Uno de los eventos que se relatan en el libro es la masacre del Aro, una de las más despiadadas y sanguinarias en las que participaron miembros del Ejército,

2 "Paras" es el mote común que se utiliza para referirse a los paramilitares en Colombia. 
CATEDRAL TomAdA: Revista de crítica literaria latinoamericana / Journal of Latin American Literary Criticism

El periodismo literario del conflicto en Colombia: Olga Behar, El clan de los doce apóstoles y María T.

Ronderos, Guerras recicladas

paramilitares y contó con el amparo de la gobernación de Antioquia. Este evento ocurrió el 25 de octubre de 1997.

Unos doscientos hombres enviados por Mancuso y Castaño llegaron al corregimiento $\mathrm{y}$, con apoyo del Ejército de Colombia, asesinaron y torturaron a quince personas, violaron a las mujeres, se robaron el ganado y forzaron el desplazamiento de todo un pueblo, más de novecientas personas. (El Clan 194)

La masacre tuvo lugar durante varios días, con hechos atroces de una magnitud inverosímil. Pese al llamado de ayuda de la población a las autoridades militares, policiales y gubernamentales, no recibieron ningún apoyo y hasta la fecha se desconocen las razones. Tiempo después uno de los criminales arrepentido, Francisco Villalba, contactó a la Fiscalía y confesó su testimonio. Relató la forma extremadamente cruel como asesinaron a las personas del pueblo y señaló a los militares y políticos que colaboraron en el acto. Además, declaró los nombres de las personalidades que planearon la acción, entre ellos los hermanos Uribe, el señor Mancuso, Cobra, Noventa, Carlos Castaño y los hombres bajo su mando. Por último, reveló que el helicóptero de la gobernación de Antioquia sobrevoló El Aro mientras se realizaba la masacre, hecho que ha sido confirmado en la investigación judicial (El Clan 199).

Villalba relató también haber estado presente en una reunión donde se tomó la decisión de asesinar a defensores de derechos humanos: Jesús María Valle, Eduardo Umaña y Jaime Garzón. Poco tiempo después Villalba fue asesinado y sus declaraciones fueron desvirtuadas y silenciadas.

La trama del libro se desarrolla en torno a un descuido del teniente Meneses en una de las operaciones que realiza en conjunto con los paramilitares, por el cual es sindicado y acusado ante la Fiscalía. Este evento le genera problemas con la ley y luego con los hermanos Uribe. Al principio estos lo amparan, pero luego lo abandonan a su suerte. Al final, cuando Meneses se ve perdido, acude a Santiago 
Uribe. Cuando este finalmente lo recibe, Meneses comete un error garrafal, le recuerda el apoyo que le prestó a sus operaciones clandestinas. Este error se convierte en su condena. Los Uribe despliegan una persecución contra él por el pecado capital de "saber demasiado". Meneses recibe amenazas y avisos alarmantes, como un sufragio que reza "muerto por sapo" (El clan 217). Uno de sus compañeros le advierte, "Oiga, ojo que Uribe está puto con usted, acuérdese que él, a todo el que le sepa cosas, intenta eliminarlo" (El clan 218). Meneses recuerda la suerte que corrieron varios de los aliados del personaje, como el Secretario de la gobernación, Juan Moreno Villa. Cuando el antiguo gobernador subió a la presidencia, Moreno se mostró en desacuerdo con él y se atrevió a manifestarlo públicamente. Terminó muerto en un accidente aéreo en circunstancias muy extrañas. "Nadie se cree el cuento de que murió en el accidente", afirma Meneses (El clan 218). Más adelante, el teniente se entera de que ya se había dado la orden de que atentaran contra él y toma la decisión de salir del país.

La narración entrelaza los elementos indispensables del texto literario: la descripción minuciosa de los espacios, la caracterización de los personajes, y el crecimiento paulatino del tono de thriller que delinea la trama. Las voces narrativas oscilan entre la confesión del entrevistado y la voz autorial. Como una novela de suspenso, el lector se convierte en testigo de los acontecimientos que conducen al teniente Meneses, primero a ser cómplice de las actuaciones del clan paramilitar, para luego huir en forma clandestina bajo las amenazas de los que antes fueran sus aliados. Al final se refugia en Argentina, donde recibe atención por parte de periodistas y activistas, incluso del Premio Nobel de Paz, Pérez Esquivel, quien se interesa por su caso. Meneses concedió entrevistas a varios medios internacionales y se convirtió en figura pública.

En el epílogo del libro Behar refiere la última entrevista con el teniente Meneses. En el transcurso del diálogo da a conocer las reflexiones que la llevan a convertir las conversaciones con él en un libro. El oficial le dice que ya había intentado contar su historia a los medios de comunicación tradicionales, pero se dio 
CATEDRAL Tomada: Revista de crítica literaria latinoamericana / Journal of Latin American Literary Criticism El periodismo literario del conflicto en Colombia: Olga Behar, El clan de los doce apóstoles y María T. Ronderos, Guerras recicladas

cuenta de que todos estaban del lado del gobierno. Cuando les daba su versión, la transmitían en contra suya. Por eso la seleccionó a ella, a quien consideró independiente y ecuánime. Para Meneses contar su historia es un intento de supervivencia y de que, si lo matan, no todo se habrá perdido: "Por eso yo conté todo, para que todo el mundo lo supiera, para que si Uribe me va a hacer algo, por lo menos lo piense mucho[...] Yo a él lo hago responsable si le llega a pasar algo a mi familia" (El clan 323).

La publicación de El clan de los Doce Apóstoles generó diversas reacciones. Como era de esperar, Olga Behar recibió una arremetida fuerte por parte de la familia Uribe Vélez, pero al mismo tiempo le llegaron decenas de comunicaciones de Yarumal. A través de cartas y diversas comunicaciones los pobladores le agradecían por haber contado la verdad. Uno de los mensajes provenía de la hija de uno de los sicarios que trabajó para el Clan, y que luego fue eliminado. Ella era un bebé cuando lo asesinaron y el libro le dio una semblanza de quién era su padre. Behar concluye:

Detrás de todas las noticias hay seres humanos, y nosotros no podemos hablar de la palabra víctima como en una nebulosa. Cada uno de los familiares de los victimarios también termina siendo víctima, como esta niña. El papá era un criminal y ella fue víctima de eso. ¡Sí! porque era una bebé, por toda la persecución y toda la estigmatización que recibió su familia, al ser la familia de este criminal. Entonces eso es lo que a uno lo regocija, eso es lo que indica que se ha cumplido con el deber, es lo más reconfortante que hay en este ejercicio profesional. (Castro Jiménez et al 70)

La autora explica que durante su carrera como periodista ha recibido elogios, críticas, y sindicaciones. Recuerda su exilio a México a raíz de la publicación de Las guerras de la paz y por dar a conocer la lista de los 
desaparecidos en el Palacio de Justicia por parte de los militares. Tuvo que exiliarse "por haberles dado voz a los que no tienen voz en este país" (El clan 310).

Es así como la crónica El clan de los doce apóstoles destapa el punctum de los horrores cometidos dentro del conflicto a partir del testimonio de uno de sus personajes, quien pasó de ser victimario a ser víctima. Porque en la dinámica de la guerra, no hay distancia entre ambos papeles y al final se funden y se difuminan. La magistralidad del texto consiste en dejar que el lector tome la decisión frente a la empatía que despierta la confesión del testimoniante y su papel en el entramado de la guerra.

\section{Guerras recicladas}

Las consideraciones éticas con respecto a las víctimas y victimarios son también una preocupación de María Teresa Ronderos, en su libro Guerras recicladas, cuando afirma:

En toda guerra, cada individuo toma decisiones éticas, y esto lo convierte en héroe o en villano, pero las circunstancias que han rodeado a los colombianos de las zonas de conflicto han sido tan apabullantes, el condicionamiento tan brutal y generalizado que borrajeó las fronteras entre víctimas y victimarios, y nubló inclusive las diferencias entre bien y mal.

Si Olga Behar descubre el entramado del poder paramilitar desde el punctum que devela el accionar de un bloque partiendo de lo particular a lo general, Ronderos despliega un panorama a nivel de país en un studium que va de lo general a lo particular.

María Teresa Ronderos posee una gran trayectoria como periodista, pero quizás lo más relevante es haber sido testigo y participe de la historia reciente de Colombia que ha retratado desde el periodismo dentro y fuera del país. Ronderos es la fundadora del Centro de Periodismo Investigativo del Latinoamérica (CLIP), 
una organización que investiga acontecimientos de interés general en países latinoamericanos. Fue directora del programa Open Society for Independent Journalism con sede en Londres hasta 2019. Es autora de Cinco en Humor (2007), Retratos del Poder (1997) y Guerras recicladas (2014). Ha sido galardonada con el premio Simón Bolívar, así como el premio Rey de España y el Lorenzo Natalí de la Unión Europea. Además, fue la primera mujer colombiana en recibir el premio María Moors Cabot de Columbia University como reconocimiento a su carrera periodística. Ronderos fue pionera en crear medios digitales de información en Colombia. En colaboración con la Fundación Ideas para la Paz fundó y dirigió el portal VerdadAbierta.com para publicar y contextualizar las realidades que no se cuentan en los medios tradicionales. Es profesora de la Fundación para un Nuevo Periodismo Iberoamericano y escribe en el diario El Espectador como columnista fija.

La crónica periodística Guerras Recicladas cuenta la historia del paramilitarismo en Colombia desde sus orígenes en los años ochenta, su fortalecimiento en los noventa en la alianza nacional conocida como Autodefensas Unidas de Colombia, hasta su desmovilización en la primera década del dos mil. La historia se nutre de detalles de cada personaje y de la conformación de cada bloque. Habla de los lazos que se tejieron entre ellos y las dinámicas que sostuvieron con las fuerzas militares, empresarios y políticos. Establece también la relación con otros sectores como el narcotráfico y bandas delincuenciales. Refiere además el proceso de desmovilización en los años 2004-2006, a través del mecanismo de justicia transicional denominado Justicia y Paz. Al final, menciona a algunas de las víctimas del paramilitarismo entre periodistas y líderes de comunidades y realiza una reflexión sobre el legado del este movimiento y sus efectos.

James E. Robinson plantea en el prólogo que el paramilitarismo surgió como respuesta a la marginación de las regiones aisladas, donde no había presencia del Estado. El libro propone que lo disfuncional y funcional coexisten y a nadie le interesa hacer nada al respecto. Explica que las élites nacionales han manejado sus 
intereses en el caos de la periferia porque las industrias de la droga, el contrabando y la expropiación ilegal de tierras les resultan beneficiosas. A raíz de la ausencia del estado, "el imperio de la ley y la violencia aparece para dirimir conflictos a falta de un tercero confiable que lo haga. Las actividades ilegales florecen y el Estado se hace el ignorante porque no le interesa dejar de percibir las ganancias que genera" (Guerras 20-21). Con estos planteamientos se anticipa la relevancia de los asuntos que se tratan en el libro.

En la introducción, Ronderos da cuenta de las cifras desmesuradas de la violencia en Colombia durante las últimas décadas: víctimas de masacres, desplazamientos, desapariciones y homicidios. Advierte que esta violencia proviene de las actuaciones de diversos bandos, incluyendo guerrilla, paramilitares y narcotráfico. Sin embargo, señala que lo interesante es que en Colombia esto ocurre no bajo una dictadura, sino dentro de una democracia en pleno funcionamiento. Para explicar esta contradicción, recupera una frase célebre del político liberal de mediados de siglo, Darío Echandía, quien declaró que "Colombia era un orangután en sacoleva". Se refería a que la violencia siempre ha existido "bajo un régimen democrático, formal con ciudadanos que viven vidas comunes y corrientes en ciudades modernas" (Guerras 25). La autora aborda la contradicción que existe entre "prosperar y ser violentos, ampliar la democracia y vivir bajo tiranías simultáneas". Se pregunta:

¿Por qué a pesar de haber ensayado alternativamente acuerdos de paz, sometimientos a la justicia y aumentos billonarios del presupuesto público de defensa y seguridad, este conflicto sangriento de Colombia no se detiene? ¿Por qué instituciones y líderes relativamente sofisticados como los colombianos se han quedado cortos en conseguir este objetivo? ¿Cómo dejaron que les saliera competencia a las tareas básicas del Estado? ¿Cómo permitieron semejante sufrimiento? ¿Por qué cuando creemos que amina la violencia, esta vuelve a resurgir? ¿Qué le permite reciclarse? ¿Por qué tantos que han querido frenar a estos ejércitos de izquierda y de derecha 
CATEDRAL TomADA: Revista de crítica literaria latinoamericana / Journal of Latin American Literary Criticism El periodismo literario del conflicto en Colombia: Olga Behar, El clan de los doce apóstoles y María T. Ronderos, Guerras recicladas

apelando a la civilidad, a la ley, a las libertades consagradas en la Constitución, se han sentido abandonados? (Guerras 26)

Estas preguntas guían la investigación en cada uno de los procesos que se relatan en el libro. La narración se basa en entrevistas personales que tuvieron lugar en la clandestinidad, otras en las cácrceles, por teléfono y medios digitales. Otorga además documentación minuiciosa obtenida en juzgados y en despachos judiciales. Ronderos hace salvedad de que el lector no encontrará la historia completa de este fenómeno, pero sí espisodios centrales que reflejan "cómo el paramilitarismo mantuvo el sello con que nació, sus influencias, los hilos ideológicos que lo forjaron y los cálculos políticos del narcotráfico" (Guerras 28).

Ronderos plantea que el objetivo del libro es mostrar las debilidades de la democracia, gracias a la cual se alimentó el paramilitarismo, con el fin de evitar otra fase expansiva de violencia. En el momento de la publicación del libro (2014), el presidente Juan Manuel Santos adelantaba la negociación del Acuerdo de paz con las FARC, y se vislumbrarba una posible pacificación. Ronderos expresa la esperanza de que "esa paz no termine en un motivo para renovar la guerra" (Guerras 27).

Como narración, el libro apela a los recursos periodisticos y literarios: descripciones de las regiones donde surgió el paramilitarismo y sus líderes más emblemáticos. Contiene relatos de trasfondo en cuanto a la vida de cada uno de ellos, las condiciones en que se criaron y los eventos que los hicieron famosos y temibles. Narra también la formación de las estructuras de poder que afianzaron su fortalecimiento y las alianzas que les ayudaron a consolidarse.

Como relato, el texto atrapa y engancha al lector. La narración es clara y fluida. Incluye diálogos, semblanzas, episodios destacados; incluso el sarcasmo e ironía están presentes. Se advierte la distancia que establece con los personajes, pero al mismo tiempo la proximidad hacia los acontecimientos. Hay una perspectiva objetiva, pero se aprecia una empatía con las víctimas y una crítica 
aguda contra las instituciones que hicieron posible este fenómeno en el país: las instituciones estatales y los medios de comunicación.

Ronderos establece así un contrapunto entre el studium y el punctum de la que habla Barthes. Por un lado, sitúa el contexto panorámico del fenónemos del paramilitarismo apuntando hacia los ingredientes sociales que lo alimentaron. Por otro, hay un subtexto muy explícito que señala y sindica a los personajes de la política y de las estructuras de poder que fueron cómplices y protagonistas en el surgimiento y consolidación de la organización con las funestas conscuencias que aun hoy siguen latentes.

Para Ronderos, la alianza del gobierno con las fuerzas paramilitares surgió de la convicción arraigada dentro de las instituciones económicas y políticas del país de que "todo se vale para desterrar el comunismo". Desde mediados de los años ochenta se acentuó la percepción del enemigo interno que incluía a todo aquel que abogara por subvertir el orden pues le daba sustento a la guerrilla para sobrevivir (Guerras 44). Esta concepción señalada por el Ministro de Defensa de los años ochenta, Fernando Landazabal Reyes, seguía las premisas de Ronald Reagan y dio la pauta para el entrenamiento de comandos militares en la famosa Escuela de las Américas ${ }^{3}$.

En esa época emergieron las escuelas de formación paramilitar apoyadas por organismos internacionales donde les enseñaban a los guerreros a odiar al comunismo y la ideología atea. Fue cuando apareció Yair Gal Klein, mercenario israelí que dictó varios cursos en Puerto Boyacá ${ }^{4}$. Los militantes aprendían no solo las técnicas de guerra, sino que recibían entrenamiento ideológico, según el cual, la guerrilla hacía daño, pero era peor el daño que ocasionaban los ideólogos y

${ }^{3}$ La Escuela de las Américas fue un centro de entrenamiento militar de Estados Unidos que funcionaba bajo las premisas de la guerra contra el comunismo. De estos centros salieron graduados con honores varios de los dictadores que rigieron los destinos de países latinoamericanos en las décadas de los setentas y ochentas. Colombia fue uno de los países con mayor número de oficiales adiestrados, más de 9,000, en contraste con 6,000 de El Salvador (Ronderos, Retratos del poder, 207).

${ }^{4}$ Sobre la historia del mercenario israelí escribió una crónica en profundidad Olga Behar titulada $E l$ caso Klein: el origen del paramilitarismo en Colombia (Icono, 2012). 
CATEDRAL TomADA: Revista de crítica literaria latinoamericana / Journal of Latin American Literary Criticism El periodismo literario del conflicto en Colombia: Olga Behar, El clan de los doce apóstoles y María T. Ronderos, Guerras recicladas

auxiliadores de la guerrilla. Esta teoría siguió siendo alimentada por varios funcionarios civiles que alentaban las operaciones antisubversivas y de limpieza social, con personajes como el profesor de la Escuela Superior de Guerra, José Miguel Narvaez con su manifiesto, "Por qué es lícito matar comunistas"5. Estos factores fueron fundamentales en la gestación de comandantes sanguinarios de la talla de los hermanos Castaño, Salvatore Mancuso, Jorge 40, Don Berna y los clanes y bloques paramilitares que operaron con tal sevicia y niveles de deshumanización como no se había visto nunca antes.

Ronderos señala que esta acometida de violencia que tuvo su mayor desafuero a finales de los años noventa (desde 1997 cuando se consolidaron las Autodefensas Unidas de Colombia, hasta los años 2007-08), fue la ignorancia en que se mantuvo a la población de las ciudades sobre los perpretadores de la misma. Los medios de comunicación daban cuenta de masacres y episodios sangrientos a lo largo y ancho del país, en los que se atribuía la culpa a la guerrilla. Esta narrativa era conveniente porque mantenía el odio y la atención en contra del enemigo a quien querían atacar, para lo cual necesitaban el apoyo concensual de la ciudadanía. Cuando se aplicaron todos los medios para acabar a los enemigos internos del gobierno, especialmente durante la administración que rigió del 2002 al 2010, la opinión pública apoyó las políticas de sometimiento y de control social. María Teresa Ronderos señala a los cómplices de esta escalada de violencia:

El paramilitarismo creció sin perro que le ladrara. Los vínculos entre militares y autodefensas se hicieron más fuertes hasta llegar a las honduras que probaron las alianzas del Batallón Popa y Jorge 40[...] Sin embargo,

\footnotetext{
${ }^{5}$ José Miguel Narváez, conocido como "El profe" fue uno de los ideólogos de los paramilitares, a quienes adiestró con su manifiesto "Por qué es lícito matar comunistas". Tuvo de estudiantes a los jefes paramilitares más sanguinarios. Durante el gobierno de Uribe trabajó como subdirector del DAS y fue el encargado de intervenir los teléfonos y seguir las actividades de todo aquel que se considerara contrario al gobierno. En 2016 fue sindicado como uno de los autores intelectuales del asesinato del periodista Jaime Garzón. (Sentencia de JM Narváez http://www.derechos.org/nizkor/colombia/doc/das364.html)
} 
a pocas autoridades nacionales les pareció que era asunto de seguridad pública preservar a periodistas y su libertad de informar. Al contrario, muchos pensaron que ellos eran los peligrosos. (Guerras 322)

El fortalecimiento de las autodefensas en convivencia con las autoridades y los medios de comunicación condujo a lo que Ronderos llama "la era Nazi":

Esta fórmula de cuatro ingredientes - poder civil nacional enclenque y dependiente, con graves ausencias de legitimidad; guerrillas criminalizadas; crimen organizado metido a pelear las guerras del Estado; y la fuerza pública dejándolo pelearlas - queda preparada en 1994 cuando muere Fidel Castaño. En los siguientes años se va haciendo densa y potente, y alimenta vigorosamente la grande expansión paramilitar de la historia colombiana que alcanzó casi todo el territorio nacional entre 1997 y 2005, y cuya herencia fue esa filosofía confusa, tan propia de la mentalidad mafiosa colombiana: odio al comunismo y a la oligarquía[...] Esta ofensiva de las autodefensas causó un dolor y un sufrimiento a millones de colombianos, que si bien ha sido documentado, denunciado, gritado, su magnitud aún no termina de calar en la conciencia urbana. Fue nuestra era nazi, pero son pocos aun los que alcanzan a concebirlo. (Mi subrayado, Guerras 220)

La autora dedica un largo segmento del libro al proceso de desmovilización de las autodefensas que tuvo lugar entre 2003 y 2006. Señala que el presidente de esa época debía otorgarle legitimidad a los grupos que él había ayudado a conformar. Ya desde antes de su posesión este personaje político supo que "necesitaba un paramilitarismo lo más presentable posible para poder negociar con él..." (Guerras 352). Como dato curioso y a la vez, escabroso, precisa que un día antes de su posesión el Presidente le escribió a su hermano (Santiago Uribe, el líder 
del Clan de los Doce Apóstoles) "pidiéndole un gesto de su parte, autorizando a sus amigos a que cerraran sus prácticas innecesarias de narcotráfico" (Guerras 352).

En realidad, durante su gobierno se hizo claro que la administración cogobernaba con los paramilitares. Esto es evidente cuando las fuerzas del Bloque Cacique Nutibara trabajaron en conjunto con la Policía, las Fuerzas Armadas y el Departamento Administrativo de Seguridad, DAS, para llevar a cabo la Operación Orión en la que atacaron por tierra y aire la Comuna 13 de Medellín como una acción de limpieza social (Guerras 356). Esta acción dejó un centenar de muertos y heridos y secuelas que aún no sanan. El gobierno se sentía en deuda con las autodefensas por su colaboración en esta empresa y los comandantes paramilitares confiaban en que habían asegurado su alianza con el poder para continuar sus acciones en el territorio.

De acuerdo con Ronderos, muchos observadores consideraron que una negociación entre el Estado y el paramilitarismo era un acuerdo de conveniencia entre amigos. Sobre este punto la autora cita un informe del International Crisis Group en el año 2003, en el que los miembros sostienen:

Existe el temor de que algunos sectores del gobierno y de las Autodefensas no se consideren realmente adversarios: se piensa que, así como ciertos elementos de las estructuras de poder tradicionales del país quizás hayan auspiciado el surgimiento de los paramilitares, también ahora quieran utilizar las conversaciones de paz para exonerarlos políticamente, y por ende, legitimar su riqueza y su poder. (Guerras 354)

Después de que se desmovilizaron los paramilitares, con penas leves y prebendas generosas, se comprobó que al menos 60 congresistas pertenecían a las autodefensas. Fue el fenómeno que se conoció como parapolítica. Varios de estos congresistas habían firmado pactos para refundar el Estado en alianza con los paramilitares. Estos pactos incluían el compromiso de que los paras obligaran a la gente a votar por ellos bajo amenazas y que condenaran a muerte a los adversarios. 
Incluso varios de ellos estuvieron de acuerdo con "que se cometieran masacres por conveniencias económicas o políticas" (Guerras 370).

Luego de sucesivos quiebres en la negociación así como la promulgación de la Ley 975 Ley de Justicia y paz de 2005, y lo que algunos consideraron incumplimiento de los acuerdos iniciales, los jefes paramilitares se sintieron traicionados y anunciaron que "contarían toda la verdad sobre cómo habían surgido, quiénes los habían apoyado y cuáles habían sido sus acciones" (Guerras 374). En un mensaje muy claro dirigido al gobierno decían: "Pedimos públicamente a quienes fueron nuestros impulsores, colaboradores y beneficiarios directos, empresarios, industriales, dirigentes políticos y gremiales, funcionarios, líderes regionales y locales, miembros de la fuerza pública[...] que nos acompañen sin aprensión ni temor en esta tarea" (Guerras 374). La advertencia era clara. Estaban dispuestos a delatar a sus auspiciadores sin miramientos, lo cual desencadenaría una conmoción a nivel estructural en el país. La respuesta del gobierno fue clara también. Decidió extraditar a casi todos los jefes más prominentes del paramilitarismo a Estados Unidos, donde eran requeridos por narcotráfico. El 13 de mayo del 2008, los grandes jefes paramilitares que habían aterrorizado al país fueron puestos en un avión rumbo a la cárcel que los esperaba en el país del norte (Guerras 377). Muchos de ellos amenazaron con contar la verdad de sus acciones y de sus alianzas, cosa que ya han hecho algunos de ellos en declaraciones a la prensa y en audiencias públicas. Otros están retornando al país después de cumplir sus condenas en 2020, y amenazan con cumplir con la retaliación, poniendo en ascuas al expresidente que los protegió y que luego los traicionó.

Los miembros de los paramilitares que no se acogieron a la amnistía de la primera década del dos mil, se adhirieron a las llamadas bandas criminales que comenzaron a surgir a partir del 2010, como las Águilas Negras, los Rastrojos y Los Urabeños Gaitanistas. Todos ellos continuaron sus operaciones cada vez más criminales y sanguinarias aprendidas con las autodefensas. Ronderos aduce que estas bandas surgieron de un proceso de paz con los paramilitares que quedó mal hecho: 
El gobierno subestimó el poder que había alcanzado a acumular el paramilitarismo en Colombia. Este fenómeno había coaptado la política regional, se había colado en el congreso con una bancada considerable de aliados y fichas propias, habían posicionado en cargos públicos a muchos de sus cómplices, no solo en las Fuerzas Armadas, sino en el gobierno nacional (desde el director del DAS hasta el jefe de seguridad de Palacio), habían acumulado millones de hectáreas de tierras, y mediante testaferros habían desarrollado grandes agroindustrias[...] y habían influido en la contratación pública hasta la recolección de impuestos distritales en el Caribe. (Guerras 379)

El gobierno no solo desestimó el poder de los paramilitares, sino los derechos de las víctimas y de los ciudadanos en general. Eso explica que hayan resurgido con tanta velocidad y fuerza las bandas criminales y que hayan seguido desempeñando sus actividades criminales, convirtiéndose en verdugos de los líderes de izquierda y de los líderes sociales y políticos por reclamos de tierras (Guerras 388). La autora documenta que entre 2009 y 2013 fueron asesinados 219 líderes sociales, culturales y de derechos humanos. En el año 2020, tras pactarse el Acuerdo de Paz y subir a la presidencia un pupilo del mandatario que gobernó durante 2002-2010, han sido asesinados más de 300 líderes sociales, de derechos humanos y ambientales, en lo que parece ser una nueva escalada de violencia producto de las mismas guerras recicladas de las que trata la narración.

En su reflexión final, Ronderos anticipa este resultado cuando afirma: “algo en la política falla estructuralmente y produce el ambiente propicio para que estos hipogrifos - medio criminales, medio políticos — se críen con facilidad en aquellos territorios de poblaciones marginadas, donde el Estado está presente pero no le funciona al ciudadano" (Guerras 380). Asegura que es necesario cambiar el modelo mismo de cómo la dirigencia nacional ha concebido y organizado la gobernabilidad política y el monopolio de fuerza en las regiones" (Guerras 381). Por último, 
advierte que hay el riesgo de que las bandas criminales como los Gaitanistas o Urabeños, "consigan desatar otra ola de paramilitarismo en unos años[...]" (Guerras 381), como en efecto lo estamos viviendo al momento de escribir este artículo (2020).

Guerras recicladas permite entrever la acción funesta del paramilitarismo en Colombia desde una mirada desapasionada, reflexiva y profundamente informada. Arroja luz sobre temas que han quedado obnubilados en la maraña de los múltiples bandos y las variadas violencias que operan en el territorio. Deja constancia de la manipulación de que han sido objeto las instituciones, los medios de comunicación y los simples ciudadanos para hacerles ver una realidad que convenía a las fuerzas involucradas y para culpar a los actores de violencia que ayudaban a afianzar las políticas de guerra, los fines políticos y económicos que beneficiaban a unos pocos. De este modo, Ronderos revela el trasfondo de uno de los fenómenos más dolorosos y espeluznantes de la historia reciente de Colombia. El conflicto colombiano y sus múltiples aristas ha representado un reto desafiante al periodismo del país. En el proceso, las formas de contar se han afinado a través de diversas técnicas para contar la verdad y construir memoria histórica. La crónica literaria, el reportaje a profundidad, la entrevista, la novela periodística y el periodismo literario, han emergido y afianzado en este intento de plasmar las múltiples caras de los hechos. Tanto Olga Behar como María Teresa Ronderos pertenecen a la misma generación de reporteras que se forjaron en medio del conflicto armado y de una sociedad en pugna. Ambas se atreven abordar desde perspectivas de riesgo el studium y sobretodo, el punctum de la historia, los sucesos que imprimen la marca de dolor en el pueblo, aquellos que siguen tratando de quedar ocultos tras las narrativas oficiales. En últimas, ellas acuden a la empatía hacia las víctimas y el sentido humano del periodismo. En palabras de Ronderos:

El periodismo debe ser solidario, sensible al sufrimiento humano; que se pone en los zapatos del otro y trata con respeto aún a los delincuentes. No concibo que el periodismo sea otro que así, humano, solidario, sensible. Si 


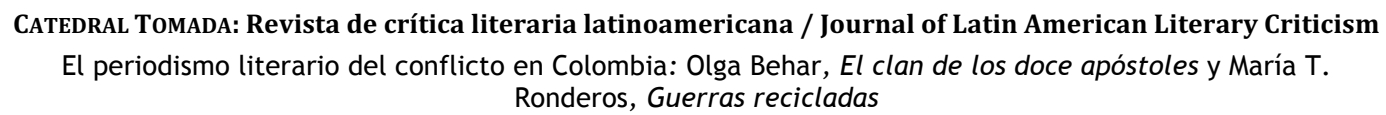

todos los periodistas trataran a sus entrevistados, y a los protagonistas de sus noticias como si se trataran de ellos mismos o de sus hijos, quizás tendríamos un país menos hirsuto, menos polarizado. (Lugo 78)

El hecho de atreverse a revelar la historia del paramilitarismo, la de sus integrantes y el impacto que este ha tenido en la historia de Colombia, supone un compromiso ético, audaz y peligroso. Algún día quizás el país acepte que este fenómeno fue uno de los mayores magnicidios de su historia, comparable con las secuelas funestas de la guerrilla, pero más reprochable por haber contado con el auspicio del Estado y de la institución militar; de los sectores económicos y políticos a nivel regional y nacional, y por haber sido el puente para entronizar el poder político durante más de dos décadas en el país.

\section{Bibliografía}

Barthes, Roland. Camera Lucida: Reflections on Photography. Richard Howard, Trad. Hill and Wang, 1981.

Behar, Olga. Las guerras de la paz. Planeta, 1985. . El clan de los doce apóstoles: conversaciones con el mayor Juan Carlos Meneses. Icono, 2011. . El caso Klein: el origen del paramilitarismo en Colombia (2012). Icono, 2012.

Castro Jiménez, María Camila, Daniela Girón Ramírez, y Stephania Ruiz Hernández. "Olga Behar, retrato de una periodista de investigación". Fundación universitaria Católica Lumen Gentium. Facultad de Ciencias Sociales y Políticas, Comunicación Social y Periodismo Santiago de Cali. Tesis. 2017.

Centro Nacional de Memoria Histórica. ;Basta Ya! Colombia: memorias de guerra y dignidad. CNMH, 2013.

Consejo de Redacción. Pistas para narrar la paz: periodismo en el posconflicto. Konrad Adenauer Stifung, KAS, 2014. . Pistas para narrar la memoria: periodismo que reconstruye las verdades. Konrad Adenauer Stiftung, 2016.

Duzán, María Jimena. ¿Para qué escribir? Debate, 2020. Edición de Kindle. 
Hoyos, Juan José. Escribiendo historias: El arte y el oficio de narrar en el periodismo. Editorial Universidad de Antioquia, 2003.

Lugo, Mary Ann. Crónica y periodismo ético en la era digital: Entrevista con María Teresa Ronderos. Revista de Estudios Colombianos. No 51, 2018. Pp. 78-80.

Morales Riviera, Antonio. Prólogo. Behar, Olga. El clan de los doce apóstoles: conversaciones con el mayor Juan Carlos Meneses. Icono, 2011. 9-15.

Puerta, Andrés. El periodismo narrativo o una manera de dejar huella de una sociedad en una época. Anagramas. Rumbos Y Sentidos De La Comunicación, vol 9, no. 18, 2011. Pp. 47-60.

https://doi.org/10.22395/angr.v9n18a3.

Ronderos, María Teresa. Retratos del poder. Planeta Semana, 2002. . Guerras recicladas: una historia periodística del paramilitarismo en Colombia. Aguilar, 2014.

Ruiz, Marta. Hechos para contar: conversaciones con 10 periodistas colombianos sobre su oficio. Penguin Random House, 2014. Ebook.

Vallejo, Mary Luz. Relatos de alta intensidad. Reseñas. Signo y Pensamiento 40. Vol. 21, 2002. Pp. 138-141. 